\title{
Optimalisasi Penggunaan Alat Berat Pada Pekerjaan Galian Tanah (Studi Kasus Proyek Perumahan Fortune Villa Graha Raya)
}

\author{
Yoggy Ramadhan ${ }^{1}$, Tri Nugraha Adi Kesuma ${ }^{1}$ \\ ${ }^{1}$ Program Studi Teknik Sipil, Universitas Pembangunan Jaya \\ tri.nugraha@upj.ac.id
}

\begin{abstract}
Heavy equipment has no longer a peculiar thing in fulfilling a construction project needs. Utilizing heavy equipment within a project can help people to realize a work and minimizing the use of time required for completing a construction work. Utilizing heavy equipment requires planning and calculation regarding the scale of the project. Construction work that being studied within this study is soil excavation within Fortune Villa project, Graha Raya, which involves several heavy equipment; 2 units of excavator, 7 units of dump truck, and 1 unit of dozer. The purpose of this study is to find out the productivity and optimization of heavy equipment utilization, viewed from the match factor of the utilization of equipment, schedule, and capital. Method utilized in this study are observation interview, and literature study. Data set taken from the study consists of primary data and secondary data. Secondary data procured from PT. Jaya Real Property and heavy equipment specification manual. Results acquired from observation alone are combination of equipment utilized in the project haven't reached the match factor of works with $M F$ value with combination value of 0.74 and 0.47 within duration of 11 days. From optimization analysis, the sum of equipment needed are acquired in the sum of 1 unit of excavator, 6 units of dump truck, and 1 unit of dozer to reach MF value of 0.92 and 0.95 within duration of 9 days. Utilizing analysis results, cost that can be saved accounted to a number of Rp. 77,439,000.00.
\end{abstract}

Keywords: Heavy equipment, excavator, dump truck, dozer, soil works, productivity, match factor

\begin{abstract}
Abstrak : Alat berat dalam dunia konstruksi bukan hal yang asing dalam memenuhi kebutuhan kerja. Dengan penggunaan alat berat dalam suatu proyek dapat membantu manusia dalam merealisasikan suatu pekerjaan dan mempersingkat waktu. Sebelum alat berat bekerja dibutuhkan perencanaan, perhitungan berdasarkan pekerjaan. Pada skripsi ini pekerjaan yang dikerjaan adalah galian tanah pada proyek Fortune Villa, Graha Raya yang melibatkan beberapa jenis alat berat; 2 unit excavator, 7 unit dump truck, dan 1 dozer. Tujuan dari penelitian ini untuk mengetahui produktivitas alat serta keoptimalan alat berat dari segi keserasian kerja alat, waktu, dan biaya. Metode penelitian yang digunakan dalam adalah observasi, wawancara, dan studi pustaka. Jenis data yang diambil adalah data primer dan sekunder. Dari hasil analisis didapat kombinasi alat yang digunakan belum memenuhi keserasian kerja dengan nilai MF masingmasing kombinasi adalah 0,74 dan 0,47 dengan durasi 11 hari. Dengan analisis optimalisasi didapatkan jumlah kebutuhan alat; 1 unit excavator, 6 unit dump truck dan 1 dozer didapat nilai MF sebesar 0,92 dan 0,95 dengan durasi 9 hari. Dengan menggunakan analisis ini terdapat penghematan biaya sebesar Rp. 77.439.000,00.
\end{abstract}

Kata Kunci : Alat berat, excavator, dump truck, dozer, produktivitas, keserasian kerja 


\section{PENDAHULUAN}

Alat berat bukan hal yang asing lagi untuk didengar dan dilihat di bidang teknik sipil. Tujuan penggunaan alat berat ini untuk membantu manusia untuk mereaslisasikan dan mempersingkat waktu dalam suatu pekerjaan konstruksi. Pada awal proyek pembangunan cluster Fortune Villa, Graha Raya dibutuhkan pemadatan tanah untuk pembentukan kontur, dimana pada proyek tersebut membutuhkan volume tanah sebesar $10.844,15 \mathrm{~m}^{3}$ dengan melalui jalan angkut 4,6 KM dari quarry ke site dan 3,6 KM dari site ke quarry. Kebutuhan alat berat berperan penting dalam pekerjaan galian tanah, Pada proyek ini menggunakan alat berat seperti excavator sebagai alat pengeruk tanah, dump truck sebagai alat pengangkut tanah, dan dozer sebagai alat penggusur tanah.

Dalam pelaksanaan pekerjaan galian tanah ini penggunaan alat berat belum memenuhi kategori optimal karena dengan kombinasi alat yang tidak sesuai dengan menggunakan 1 unit excavator Kobelco SK-200, 1 unit excavator Hitachi EX-200, 7 unit dump truck, dan 1 unit dozer Caterpillar D6D membuat alat-alat tersebut belum memenuhi keserasian kerja yang baik sehingga dapat membuat alat-alat tersebut saling menunggu alat berat lainnya yang membuat target target produksi yang berkurang, serta semakin lamanya durasi alat tersebut bekerja membuat biaya pengeluaran yang lebih besar.

Penelitian ini memaparkan optimalisasi dan keserasian kerja konstruksi ditinjau dari segi waktu dan biaya penggunaan alat berat pada kegiatan proyek konstruksi.

\section{KAJIAN PUSTAKA}

\section{Alat Berat}

Dalam ilmu teknik sipil alat berat merupakan alat yang digunakan untuk membantu manusia dalam melakukan pekerjaan pembangunan suatu struktur bangunan (Rostiyanti, 2008). Alat berat merupakan faktor penting di dalam suatu proyek karena tujuannya dapat memudahkan manusia dalam melakukan pekerjaannya sehingga hasil pekerjaannya dapat terealisasikan dengan lebih mudah pada waktu yang relatif lebih singkat.

\section{Alat Berat pada Pekerjaan Galian Tanah}

Pada pekerjaan galian tanah, alat berat yang berperan penting yakni excavator sebagai alat pengeruk material, dump truck sebagai alat pengangkut material, dan dozer sebagai alat penggusur dan perataan material. Alat-alat ini merupakan kombinasi ideal yang dilakukan kontraktor untuk pekerjaan galian tanah. (www. ritchiespecs.com)

\section{Excavator}

Excavator adalah alat berat yang selalu ada dalam kegiatan konstruksi awal, alat berat ini merupakan alat yang berperan penting dalam pekerjaan galian tanah. Alat berat ini bekerja dengan mengeruk atau menggali material dengan menggunakan bucket yang dipasangkan di bagian depan yang ada dibawah permukaan tanah ataupun diatas alat itu sendiri untuk dipindahkan ke suatu tempat yang telah ditentukan ataupun memuat ke suatu alat berat untuk memindahkan. (www. ritchiespecs.com)

\section{Dump truck}

Dump truck adalah suatu kendaraan yang digunakan untuk memindah material berupa tanah, pasir, dan bahan untuk konstruksi lainnya yang telah dimuat oleh excavator ke dalam bak yang berada dibagian belakang dengan jarak mengenah sampai jarak jauh (500 $\mathrm{m}$ atau lebih). Seperti yang diketahui material yang telah terisi di bagian bak akan dibongkar oleh dump truck sendiri di suatu lokasi yang telah ditentukan. (www. ritchiespecs.com)

\section{Dozer}


Dozer adalah alat berat semacam traktor dengan pisau pendorong yang terletak dibagian depan. Pisau berfungsi untuk penggusuran atau perataan suatu material yang telah dibongkar oleh dump truck hingga pada bagian depan penuh ke tempat yang telah ditentukan. (www. ritchiespecs.com)

\section{Job efficiency}

Dalam pelaksanaan pekerjaan yang menggunakan alat berat terdapat beberapa faktor yang mempengaruhi produktivitas suatu alat tersebut. Faktor itu seperti berikut:

1) Faktor cuaca

2) Faktor kondisi medan

3) Faktor material

4) Faktor manajemen (metode pelaksanaan dan pekerjaan)

5) Faktor pemilihan dan pemeliharaan alat

6) Kemampuan operator

Untuk menentukan job efficiency suatu alat maka dapat menggunakan cara meninjau waktu efektif kerja alat dalam satu jam kerja dan yang kedua menggunakan faktor teoritis dalam satu jam yang dirangkum pada tabel efisiensi kerja.

Tabel 1. Efisiensi Kerja Alat

\begin{tabular}{lllll}
\hline \multirow{2}{*}{$\begin{array}{l}\text { Con } \\
\text { Conditions }\end{array}$} & \multicolumn{4}{l}{ Management Conditions } \\
\cline { 2 - 5 } Excellent & Good & Fair & Poor \\
Eood & 0,84 & 0,81 & 0,76 & 0,70 \\
Fair & 0,78 & 0,75 & 0,71 & 0,65 \\
Poor & 0,72 & 0,69 & 0,65 & 0,60 \\
\multicolumn{5}{c}{ Sumber: Construction Methods and } \\
Management, 2006
\end{tabular}

\section{Waktu Siklus Excavator}

Waktu siklus excavator terdiri dari 4 komponen yaitu:

1. Waktu mengisi bucket (excavating time)

2. Waktu putar bermuatan saat, muatan penuh (loaded swing time),

3. Waktu membongkar muatan (dumping time),
4. Waktu putar bermuatan kosong/kembali (empty swing time).

Keempat gerakan tersebut menentukan lama waktu siklus excavator, namun waktu siklus ini juga tergantung dari ukuran excavator, excavator yang kecil waktu siklusnya akan lebih cepat dibandingkan dengan excavator ukuran besar, dan tentu saja kondisi kerja berpengaruh. Tanah yang sulit digali juga mempengaruhi waktu.

$$
C_{m s}=t_{m}+t_{p b}+t_{b}+t_{p k}
$$

Dengan,

$C_{m s}=$ Waktu siklus excavator (detik)

$t_{m} \quad=$ Waktu muat bucket (digging time) (detik)

$t_{p b} \quad=$ Waktu putar bermuatan (detik)

$t_{b} \quad=$ Waktu Buang (detik)

$t_{p k} \quad=$ Waktu mengayun saat muatan kosong (detik)

\section{Waktu Siklus Dump Truck}

Waktu siklus dump truck terdiri dari:

1. Waktu muat

2. Waktu pengangkutan

3. Waktu pembongkaran muatan

4. Waktu kembali

5. Waktu antri

$$
\mathrm{C} m t=(\mathrm{n} \times \mathrm{Cms})+\frac{\mathrm{D}}{\mathrm{V} 1}+\mathrm{t} 1+\frac{\mathrm{D}}{\mathrm{V} 2}+\mathrm{t} 2
$$

Dengan

$C_{m t} \quad=$ Waktu siklus dump truck (menit)

$n \quad=$ Jumlah siklus yang diperlakukan excavator

$C_{m s} \quad=$ Waktu siklus excavator (jam)

$D \quad=$ Jarak angkut dump truk $(\mathrm{km})$

$V_{1} \quad=$ Kecepatan rata-rata truk muatan $(\mathrm{km} / \mathrm{jam})$

$V_{2} \quad=$ Kecepatan rata-rata truk kosong $(\mathrm{km} / \mathrm{jam})$

$t_{1} \quad=$ Waktu buang (jam)

$t_{2}=$ Waktu antri (jam)

\section{Waktu Siklus Dozer}

Waktu siklus dozer terdiri dari waktu menggusur, waktu ganti perseneling, dan waktu mundur kembali. 
Dengan,

$$
\mathrm{Cm}=\frac{\mathrm{D}}{\mathrm{F}}+\frac{\mathrm{D}}{\mathrm{R}}+\mathrm{Z}
$$

$D \quad$ : Jarak angkut (m)

F : Kecepatan Maju (m/menit)

$R \quad$ : Kecepatan mundur (m/menit)

$Z \quad$ : Waktu ganti gigi (menit)

\section{Produktivitas Alat Berat pada Pekerjaan Tanah}

Dalam pekerjaan pemindahan tanah secara mekanik dibutuhkan perencanaan yang tepat agar alat tersebut memiliki produktivitas yang tinggi.

\section{Produktivitas Excavator}

Perhitungan produktivitas perjam excavator dipengaruhi oleh efisiensi kerja, ukuran bucket dan faktor koreksi bucket excavator itu sendiri.

$$
\mathrm{Q}=\frac{\mathrm{q} \times 3600 \times \mathrm{E}}{\mathrm{Cms}}
$$

Dengan,

$$
\begin{array}{ll}
Q & =\text { Produksi perjam }\left(\mathrm{m}^{3} / \mathrm{jam}\right) \\
q & =\text { Produksi per siklus }\left(\mathrm{m}^{3}\right) \\
C_{m s} & =\text { Waktu siklus excavator (detik) } \\
E & =\text { Efisiensi kerja }
\end{array}
$$

Dimana $q$ adalah:

Dengan,

$$
q=q 1 \times K
$$

$q \quad=$ Produksi per skilus $\left(\mathrm{m}^{3}\right)$

$q_{l} \quad=$ Kapasitas bucket $\left(\mathrm{m}^{3}\right)$

$K=$ Faktor pengisian bucket

\section{Produktivitas Dump Truck}

Perhitungan produktivitas perjam dump truck dapat dihitung dengaan persamaan sebagai berikut:

$$
Q=\frac{C \times 60 \times E \times N}{C m t}
$$

Dengan,

$$
\begin{array}{lll}
Q & =\text { Produksi perjam }\left(\mathrm{m}^{3} / \mathrm{jam}\right) \\
C_{m t} & =\text { Waktu siklus dump truck (menit) } \\
E & =\text { Efisiensi kerja } \\
N & =\text { Jumlah dump truck yang } \\
& \text { beroperasi }
\end{array}
$$

Dimana $C$ adalah:

$$
C=n \times q 1 \times K
$$

Dengan:

$$
C \stackrel{=}{C} \text { Produksi per siklus }\left(\mathrm{m}^{3}\right)
$$

$$
\begin{array}{ll}
n & =\text { Jumlah siklus dari excavator } \\
& \text { mengisi dump truck } \\
q_{1} & =\text { Kapasitas bucket excavator }\left(\mathrm{m}^{3}\right) \\
K & =\text { Faktor bucket }
\end{array}
$$

\section{Produktivitas Dozer}

Produktivitas perjam dozer dapat dihitung dengan persamaan sebagai berikut:

$$
Q=\frac{q \times 60 \times E}{C m}
$$

Dengan,

$$
\begin{array}{ll}
Q & =\text { Produksi perjam }\left(\mathrm{m}^{3} / \mathrm{jam}\right) \\
q & =\text { Produksi per siklus }\left(\mathrm{m}^{3}\right) \\
C_{m} & =\text { Waktu siklus (menit) } \\
E & =\text { Efisiensi kerja }
\end{array}
$$

Dengan $q$ adalah:

Dengan,

$$
q=L \times H^{2} \times a
$$

$$
\begin{array}{ll}
q & =\text { Produksi per siklus } \\
L & =\text { Lebar blade } \text { (meter) } \\
H & =\text { Tinggi blade (meter) } \\
a & =\text { faktor blade }
\end{array}
$$

\section{Keserasian Kerja (Match Factor)}

Keserasian kerja adalah dimana suatu alat yang bekerja secara berseri ketergantungan dengan arti tidak adanya waktu tunggu untuk masing-masing alat yang membuat produksi tidak optimal. Untuk menentukan nilai keserasian kerja dapat menggunakan persamaan sebagai berikut:

Dengan,

$$
\mathrm{MF}=\frac{\mathrm{Na} \times \mathrm{n} \times \mathrm{Cms}}{\mathrm{Nm} \times \mathrm{Cmt}}
$$

$$
\begin{array}{rlr}
M F & =\text { Match Factor } \\
N_{a} & =\text { Jumlah dump truck dalam } \\
& \text { kombinasi kerja (unit) } \\
n & =\quad \text { Banyaknya siklus untuk } \\
& \text { pengisian } \\
& \text { satu dump truck } \\
C_{m s} & =\text { Waktu siklus } \text { excavator (menit) } \\
N_{m} & =\text { Jumlah excavator dalam } \\
& \text { kombinasi kerja (unit) } \\
C_{m t} \quad= & \text { Waktu siklus dump truck (menit) }
\end{array}
$$

Jika hasil yang diperoleh sebagai berikut:

a) $\mathrm{MF}<1$, maka produktivitas excavator lebih besar dari dump truck, sehingga terdapat waktu 
tunggu bagi excavator karena menunggu dump truck yang belum datang.

b) $\mathrm{MF}=1$, maka produktivitas alat tersebut sama, sehingga tidak terjadi waktu tunggu diantara kedua alat tersebut.

c) $\mathrm{MF}>1$, maka produktivitas dump truck lebih besar dibanding excavator, sehingga terdapat waktu tunggu bagi dump truck untuk memulai pengisian.

\section{Kebutuhan Alat Berat}

Dalam perencaan suatu pekerjaan galian tanah, jumlah alat adalah akhir dari perencanaan tersebut. Dengan itu dapat menggunakan persamaan sebagai berikut:

- Menentukan kebutuhan dump truck:

$$
\mathrm{m}=\frac{\mathrm{Q} \text { excavator }}{\mathrm{Q} \text { dump truck }}
$$

- Menentukan kebutuhan excavator:

$$
\mathrm{n}=\frac{\mathrm{V}}{\mathrm{We} \times \mathrm{S} \times \mathrm{Q}}
$$

Dengan,

$n \quad=$ Jumlah unit excavator

$V \quad=$ Volume perjenis pekerjaan $\left(\mathrm{m}^{3}\right)$

$W_{e} \quad=$ Waktu efektif hari kerja (hari)

$S \quad=$ Standart jam kerja perjari (jam/hari)

$Q \quad=$ Produksi persatuan waktu

- Menentukan kebutuhan dozer:

$$
\mathrm{n}=\frac{\mathrm{V}}{\mathrm{We} \times \mathrm{S} \times \mathrm{Q}}
$$

Dengan,

$n=$ Jumlah unit excavator

$V \quad=$ Volume perjenis pekerjaan $\left(\mathrm{m}^{3}\right)$

$W_{e} \quad=$ Waktu efektif hari kerja (hari)

$S \quad=$ Standard jam kerja perjari (jam/hari)

$Q \quad=$ Produksi persatuan waktu

\section{Durasi Pekerjaan}

Untuk menghitung durasi pekerjaan tiap alat dapat menggunakan persamaan sebagai berikut:

$$
\mathrm{n}=\frac{\text { Volume Tanah }}{\text { Produksi alat terkecil } \times \text { jam kerja }}
$$

Pengumpulan data bertujuan mendapatkan seluruh data/informasi yang dibutuhkan untuk penelitian ini. Pengambilan data dilakukan dengan cara:

1. Observasi

2. Studi Pustaka

3. Wawancara

Adapun data-data primer yang digunakan terdiri dari:

- Faktor kerja

- Waktu siklus alat berat

- Biaya sewa

- Jarak angkut untuk memindahkan tanah

Data Sekunder terdiri dari:

- Data Tanah

- Spesifikasi Alat

- Grading site plan

Setelah data-data didapatkan, dilakukan analisis produktivitas aktual yang didapatkan dengan menghitung waktu siklus ideal tiap alat dengan menghitung waktu siklus ideal tiap alat dengan efisiensi kerja yang ditetapkan pada data lapangan.

Analisis yang dihasilkan lalu dihitung biayanya dan dibandingkan dengan kejadian di lapangan.

\section{HASIL PENELITIAN DAN ANALISIS Tinjauan Proyek}

Proyek pekerjaan galian tanah pada proyek pembangunan cluster Fortune Villa, Graha Raya memiliki kebutuhan tanah sebanyak 10.844,15 $\mathrm{m}^{3}$. Kondisi tanah yang dipindahkan berupa tanah yang sudah dikeruk oleh excavator maka dari itu tidak adanya biaya gali. Dengan jalur angkut ke pembuangan sepanjang 4,6 km dan jalur kembali ke quarry sepanjang 3,6 km. Pada proyek ini menggunakan alat berat sebagai berikut: "Excavator A" Kobelco SK-200 (heaped bucket capacity: 0,93 $\mathrm{m}^{3}$ ), "Excavator B" Hitachi EX200 (heaped bucket capacity: $1,2 \mathrm{~m}^{3}$ ), 7 unit dump truck $20 \mathrm{~m}^{3}$, dan 1 unit Caterpillar D6D dengan lebar pisau 3,2 $\mathrm{m}$ dan tinggi pisau 1,12 $\mathrm{m}$.

\section{Job efficiency}


Terdapat faktor-faktor yang mempengaruhi efisiensi pada proyek ini, dan didapat waktu efektif hanya 40 menit dalam 1 jam kerja.

\section{Kombinasi Alat Berat Aktual}

Setelah meninjau alat yang digunakan pada proyek ini dapat diketahui kombinasi yang digunakan untuk alat muat dan alat angkut di quarry seperti ditunjukkan Tabel 2.

\section{Produktivitas Excavator}

- Excavator A 130,60 m³ $/ \mathrm{jam}$

- Excavator B 165,29 m³/jam

Tabel 2. Kombinasi Alat Muat-Angkut

\begin{tabular}{clcc}
\hline No & \multicolumn{1}{c}{ Jenis } & $\begin{array}{c}\text { Excavat } \\
\text { or }\end{array}$ & $\begin{array}{c}\text { Dump } \\
\text { truck }\end{array}$ \\
\hline $\mathbf{1}$ & Kombinasi I & 1 unit A & 4 unit \\
\hline 2 & Kombinasi II & 1 unit B & 3 unit
\end{tabular}

Dump truck diserikan dengan excavator A menghasilkan produktivitas 24,197 $\mathrm{m}^{3} /$ jam. Bila Dump truck diserikan dengan excavator B menghasilkan produktivitas $26,199 \mathrm{~m}^{3} / \mathrm{jam}$. Sedangkan produktivitas Dozer adalah sebesar $141,78 \mathrm{~m}^{3} / \mathrm{jam}$.

\section{Tinjauan Terhadap Waktu Aktual}

Karena excavator dan dump truck bekerja saling berseri maka diambil durasi terlama yaitu 11 hari dan dozer karena bekerja bergantung dengan tanah yang sudah dipindahkan maka durasi dozer menjadi 11 hari.

Tabel 3. Waktu Aktual Alat Berat

\begin{tabular}{clc}
\hline No & \multicolumn{1}{c}{ Jenis Alat } & Durasi \\
\hline $\mathbf{1}$ & Excavator & 11 \\
\hline $\mathbf{2}$ & Dump truck & 8 \\
\hline $\mathbf{3}$ & Dozer & 10
\end{tabular}

\section{Keserasian Kerja (Match factor) Aktual}

Kombinasi aktual dilapangan pada kombinasi I sebesar 0,74 dan kombinasi II sebesar 0,47. Dengan hasil tersebut dapat disimpulkan bahwa dua kombinasi alat yang digunakan masih belum memenuhi keserasian kerja yang baik, terdapat waktu tunggu excavator karena dump truck yang belum kembali ke quarry.

\section{Rekomendasi Kebutuhan Alat}

Setelah mendapatkan nilai MF yang belum memenuhi keserasian kerja yang telah dianalisis sebelumnya, maka dibutuhkan rekomendasi perencanaan kebutuhan untuk masing-masing alat.

Tabel 4. Kebutuhan Alat Kombinasi I

\begin{tabular}{|c|c|c|}
\hline No & Jenis Alat & Rekomendasi \\
\hline 1 & Excavator & 1 tipe $\mathrm{A}$ \\
\hline 2 & Dump truck & 5 \\
\hline 3 & Dozer & 1 \\
\hline \multicolumn{3}{|c|}{ Tabel 5. Kebutuhan Alat Kombinasi Il } \\
\hline No & Jenis Alat & Rekomendasi \\
\hline 1 & Excavator & 1 tipe $\mathrm{B}$ \\
\hline 2 & Dump truck & 6 \\
\hline 3 & Dozer & 1 \\
\hline
\end{tabular}

\section{Analisis Keserasian Kerja (Match factor)}

Dengan menggunakan rekomendasi kebutuhan alat, maka dapat dihitung nilai MF untuk masing-masing kombinasi alat.

Tabel 6. Perbandingan Keserasian Kerja Alat Aktual dan Optimalisasi

\begin{tabular}{cccc}
\hline No & Jenis & Sebelum & Sesudah \\
\hline $\mathbf{1}$ & Kombinasi I & 0,74 & 0,93 \\
\hline $\mathbf{2}$ & Kombinasi II & 0,47 & 0,95 \\
\hline
\end{tabular}

Setelah mendapatkan untuk masingmasing kombinasi, dengan mengambil nilai MF tertinggi maka diambil kombinasi II untuk melakukan pekerjaan ini.

Tabel 7. Perbandingan Penggunaan Alat Aktual dengan Rekomendasi

\begin{tabular}{clcc}
\hline No & Jenis Alat & Existing & Rekomendasi \\
\hline $\mathbf{1}$ & Excavator & 2 & 1 tipe B \\
\hline $\mathbf{2}$ & $\begin{array}{l}\text { Dump } \\
\text { truck }\end{array}$ & 7 & 6 \\
\hline $\mathbf{3}$ & Dozer & 1 & 1 \\
\hline
\end{tabular}

Analisis Waktu dan Biaya Aktual dan Biaya operasional timbul ketika alat berat digunakan. Untuk mengetahui biaya alat berat pada proyek. Semakin lama suatu pekerjaan maka semakin mahal biaya yang 
harus dikeluarkan untuk suatu pekerjaan menggunakan alat berat.

Tabel 8. Perbandingan Waktu Aktual dengan Rekomendasi

\begin{tabular}{cccc}
\hline No & Alat & Sebelum & Sesudah \\
\hline $\mathbf{1}$ & Excavator & 11 hari & 9 hari \\
\hline $\mathbf{2}$ & Dump truck & 11 hari & 9 hari \\
\hline $\mathbf{3}$ & Dozer & 11 hari & 10 hari
\end{tabular}

Perbandingan biaya antara kondisi aktual dengan kondisi rekomendasi ditampilkan dalam Tabel 9 berikut ini.

Tabel 9. Perbandingan Biaya

\begin{tabular}{|c|c|c|c|}
\hline Kambimasi & $\mathrm{six}$ & Durasi & Total Bixya \\
\hline \multirow{4}{*}{ aktual } & I uir.excavater A & II & \multirow{4}{*}{ F. 22229$] 3.000,00$} \\
\hline & 1 wh: excwate B & 11 & \\
\hline & 7 urit d.linp tack. & Il & \\
\hline & I Irit dozer & 11 & \\
\hline \multirow{3}{*}{ Relannaudasi } & 1 uriexcavatu B & 9 & \multirow{3}{*}{ Fo. $145454.000,10$} \\
\hline & 6 unit d.ang tack & 9 & \\
\hline & I Irit dhat & 10 & \\
\hline
\end{tabular}

Dari nilai tersebut dapat disimpulkan terdapat waktu tunggu excavator karena dump truck yang belum kembali ke quarry. Dengan menggunakan kombinasi aktual durasi dan biaya yang dikeluarkan sebesar Rp.222.903.000,00 untuk 11 hari kerja. Setelah dilakukan optimalisasi diketahui jumlah yang seharusnya digunakan sebanyak 1 unit excavator A, 5 unit dump truck, dan 1 unit dozer untuk kombinasi I dan 1 unit excavator B, 6 unit dump truck, dan 1 unit dozer untuk kombinasi II. Nilai MF untuk kombinasi I dan kombinasi II mengalami peningkatan menjadi 0,92 dan 0,95 maka dari itu dengan mengambil nilai MF tertinggi dapat diputuskan kombinasi II untuk melakukan pekerjaan ini. Dengan kombinasi II durasi pekerjaan 9 hari untuk excavator-dump truck bekerja dan 10 hari untuk dozer bekerja dan terdapat penghematan pengeluaran sebesar Rp.77.439.000,00.
Karena itu, pihak kontraktor pelaksana disarankan untuk menggunakan satu unit excavator B berseri dengan unit dumptruck berkapasitas $20 \mathrm{~m}^{3}$ dan satu unit dozer Caterpillar D6D untuk mengurangi biaya dan mempercepat durasi pekerjaan.

\section{DAFTAR PUSTAKA}

1. Kementerian PUPR, Lampiran Peraturan Menteri Pekerjaan Umum dan Perumahan Rakyat Nomor: 28/PRT/M/2016 Tentang Analisis Harga Satuan Pekerjaan Bidang Pekerjaan Umum, Indonesia, 2016.

2. Nujum, K, Ag. Isjudarto, A.A. Inung Arie Adnyano, Keserasian Kerja Alat Gali-Muat dan Alat Angkut Pada Kegiatan Pengambilan Lumpur dan Tanah Pucuk di PT. Newmont Nusa Tenggara Kabupaten Sumbawa Barat, Provinsi Nusa Tenggara Barat, Jurnal. STTN, 2015.

3. Nunnaly, Stephen W., Construction Methods and Management 7th Ed., Pearson Prentice Hall, Columbus, New Jersey: USA, 2006.

4. Peurifoy, R., Construction, Planning Equipment and Methods 7th Ed. McGraww-Hill, Boston, Massachussets: USA, 2005.

5. Rostiyanti, S.F., Alat berat untuk Proyek Konstruksi, Edisi Kedua. Rineka Cipta, Jakarta, 2008.

6. Sutanto, K.R., Kosasi, M.H., Andi. Produktivitas Alat Berat pada Pekerjaan Galian Gedung P1 P2 UK Petra, Jurnal, Universitas Kristen Petra, Surabaya.

7. Yadam, R. W, Diputra, I Gede A., Sudipta, I Gusti K., Optimalisasi Penggunaan Alat Berat Pada Pekerjaan Galian Tanah (Studi Kasus: Proyek Pembangunan Stock Yard Suzuki Negara, Kab. Jembrana, Bali), Jurnal, Universitas Udayana, Bali, 2015.

8. https://www.kobelcocmglobal.com/products/asia/SK200- 
8_SK210LC-8_mic.html, diakses Tanggal 20/1/18

9. www.ritchiespecs.com/specification?type $=$ $\&$ category $=$ Crawler + Tractor $\&$ make $=\mathrm{Ca}$ terpillar\&model=D6D\&modelid=90783, diakses tanggal 20/1/18

10. www.ritchiespecs.com/specification?t ype $=$ construction+equipment \&category $=$ Hydraulic+Excavator\&make=Hitachi\&m odel=EX200-5\&modelid=104030, diakses tanggal 20/1/18

11. www.ritchiespecs.com/specification?t ype $=$ construction+equipment\&category $=$ Hydraulic + Excavator $\&$ make $=$ Kobelco $\&$ model $=$ SK200- $8 \&$ modelid $=106251$, diakses tanggal 20/1/18 